\title{
Living Apart Relationships in Contemporary Europe: Accounts of Togetherness and Apartness
}

\section{Mariya Stoilova}

Birkbeck, University of London, UK

\section{Sasha Roseneil}

Birkbeck, University of London, UK

\section{Isabel Crowhurst}

Kingston University, UK

\section{Tone Hellesund}

University of Bergen, Norway

\section{Ana Cristina Santos}

University of Coimbra, Portugal

\begin{abstract}
Drawing on a European cross-national biographical-narrative study of intimate life, this article discusses the complexity of experiences of 'togetherness' and 'apartness' amongst people in living apart relationships. We explore the five main ways in which interviewees spoke about and understood their current living apart relationships (as: chosen; temporary; transitional; undecided; and unrecognisable), which we argue shows the need for a broader conceptualisation of this form of intimate relationship than is suggested by the established notion of 'living apart together'. The article points to interviewees' varying experiences of receiving or being denied recognition and acceptance by others as belonging to a couple, as well as to their differing degrees of desire for, or rebellion against, expectations that living apart relationships should 'progress' towards cohabitation.
\end{abstract}

\section{Keywords}

biographical-narrative interviews, cohabitation, couple relationship, intimacy, living apart together, recognition

\section{Corresponding author:}

Mariya Stoilova, Birkbeck, University of London, Malet Street, London WCIE 7HX, UK.

Email:m.stoilova@bbk.ac.uk 


\section{Introduction}

Relationships in which the intimate parties do not cohabit have been an increasing focus of social research over the past decade. In Europe, North America, and Australia between 6 per cent and 10 per cent of adults are in relationships in which they do not live with their partner (Haskey, 2005; Levin, 2004; Strohm et al., 2009). It is suggested that such relationships are increasingly socially significant (Roseneil, 2006) and that their number has been increasing amongst all age groups (Allan et al., 2001; Haskey, 2005; Levin, 2004). There is considerable diversity amongst this group (Duncan and Phillips, 2010; Duncan et al., 2013), with people having a wide variety of reasons for living apart, experiencing varying degrees of choice and constraint, understanding their relationships in differing ways, and coming to their relationships through diverse routes, at different times in their lives (Haskey and Lewis, 2006; Roseneil, 2006). The increased prevalence and visibility of these relationships is seen as related to changing norms about intimacy and the diversification of partnering and parenting arrangements (Duncan and Phillips, 2010; Roseneil, 2006), and as associated with women's increasing economic independence (Holmes, 2004). They are also seen as being linked to improved standards of living, longer life expectancy, increased geographical mobility (Levin and Trost, 1999), and new communication technologies (Holmes, 2004).

Whilst there is a long history of married couples living apart, traditionally because of the demands of the husband's work (Gerstel and Gross, 1984) or immigration regulations (Beck-Gernsheim, 2007), recent research has extended the focus beyond the study of married couples and the exigencies of paid employment to explore the heterogeneity of circumstances that surround couples who live apart. Yet, despite an implicit recognition that new modes of coupledom are in evidence amongst people who live apart, there is a tendency in the literature to seek to distinguish 'true' living apart relationships those that can be defined as 'serious' (Ermisch and Siedler, 2009: 31), 'regular' (Haskey and Lewis, 2006: 39), or 'steady' (Reimondos et al., 2011: 45) - from those relationships which are deemed temporary and therefore insignificant. In the absence of formal markers of coupledom - such as marriage or civil partnership, a shared surname, common children, or the informal but now widely recognised indicator of co-residence (Roseneil, 2006) - living apart relationships do not have an easily defined 'cut-off point' (Duncan and Phillips, 2010). So, researchers have often sought to identify the 'real' living apart relationships - those that are 'mature' and 'committed'. In contrast, in this article we adopt a less 'categorical' and more exploratory approach to the study of non-cohabiting relationships, which does not determine in advance which count as such, beyond an individual's self-identification as being 'in a relationship with someone with whom they do not live'. We seek instead to investigate such relationships in their diversity and to allow space for both those that are more readily recognised within dominant ways of thinking about intimacy, and those that are potentially more unusual or counter-normative in form.

We also depart from the established terminology that describes non-cohabiting relationships as 'living apart together' (LAT) relationships (Levin and Trost, 1999), a term which is gradually entering wider public discourse. Our focus in this article is on interrogating what it means to be in a relationship when living apart: we explore 
both 'togetherness' and 'apartness', posing as an empirical question what might be the meanings and experiences of both intimacy and distance when living apart. We choose to refer, more neutrally, to 'living apart relationships' (LARs), rather than 'living apart together' (LAT) relationships, because this latter terminology seems to over-emphasise the 'togetherness' of the relationship that we think should be a matter of empirical investigation. ${ }^{1}$ Drawing on a sample of people in LARs in four European countries with whom we carried out in-depth biographical-narrative interviews, we seek to understand our interviewees' relationships on their own terms - through their narratives and in the context of their biographies.

\section{Living Apart in Four Contrasting National Contexts}

The research on living apart relationships presented here was part of a larger study of intimate citizenship in multicultural Europe ${ }^{2}$ that focused on people living outside conventional familial relations. ${ }^{3}$ The study was carried out in four contrasting national contexts - Norway, the UK, Bulgaria, and Portugal. The selection of the countries was based on a 'most different' comparative research design that comprised a 'social democratic' Nordic welfare state, a 'liberal' or - more recently, a 'social investment' - welfare state, a 'post-communist' state, and a 'Southern European', post-dictatorship state.

The availability of data on the prevalence and characteristics of living apart relationships varies across these four countries. Whilst there have been a number of studies in the UK, and fewer on Norway and Bulgaria, there has been no national representative survey of living apart in Portugal. Large scale surveys of family life have only recently started to distinguish non-residential relationships, having tended previously to regard people who were not married or cohabiting as single (Roseneil, 2006).

The most recent data on the UK suggests that about 10 per cent of adults are in a relationship but do not live with their partner, which is a quarter of those who are not married or cohabiting (Duncan et al., 2013). A similar proportion, 13 per cent, of Bulgarian adults does not live with their partner, while in Norway the figure is over 28 per cent (UN, 2010). ${ }^{4}$ Bulgarian people in LARs are younger on average than in the other countries; the Norwegians are more evenly spread across the age groups, while the UK living apart group is somewhere in the middle. Previous research explains the prevalence of nonresidential relationships in Eastern Europe (e.g. Bulgaria) and in Southern Europe (which would include Portugal) in terms of the expansion of higher education, the low affordability of housing, and cultural preferences resulting in progressively delayed home leaving patterns of young adults (Sobotka and Testa, 2008). The Generations and Gender Survey (UN, 2012) found that slightly under half of those surveyed in Bulgaria lived apart because of housing, financial difficulties, or the demands of work, and over half thought they were not ready to live together. Yet, three in 10 people also lived apart to keep their independence (UN, 2012). Similarly, studies in the UK and Norway suggest that both preference and constraint play a role in living apart arrangements (Duncan and Phillips, 2010; Duncan et al., 2013; Levin, 2004). In contrast to Eastern and Southern Europe, where living apart relationships tend to be understood in terms of delay in leaving the parental home, in Western Europe and Nordic countries it is often linked to greater popularity of solo-living (Jamieson et al., 2009; Roseneil, 2006). The number of 
people living alone has risen over the past decade in all four countries, most significantly in Bulgaria, and in 2011 a fifth of the households in Portugal, three in 10 households in the UK and Bulgaria, and four in 10 in Norway consisted of a person living alone (UNECE, 2012).

\section{Sample and Methodology}

Not wanting to assume in advance which relationships in a person's life were the most important or meaningful, we used the biographical-narrative interpretive method (BNIM) (Roseneil, 2012; Wengraf, 2001) which encourages the interviewee to speak as freely as possible in response to a single initial question: 'can you tell me the story of your life and personal relationships, all the events and experiences important to you?'. Whilst the interviewees knew that they were asked to participate because they were in a non-cohabiting relationship, we did not focus explicitly on this but sought to elicit narratives of 'life and personal relationships' more generally. After the response to the initial question (which varied in length between 6 minutes and 2 hours 53 minutes), the interviewer embarked on a process of seeking further narrative detail about events and experiences that had been mentioned by the interviewee. The interviews lasted between 28 minutes and 4 hours 9 minutes, with a mean length of 2 hours and 11 minutes. In contrast to a traditional semistructured interview, this method allows much greater space for the relationship meanings of the interviewee to emerge spontaneously, and to be understood, in vivo, within the context of the overall biographical-narrative that they offered (Roseneil, 2012).

We interviewed 21 people who were in living apart relationships (14 women and seven men), of whom 13 were members of national majority populations and eight were from minoritised groups (Roma, Turkish, Pakistani, or Sami). Our relatively small sample consisted of people in their 30s and 40s (and one in his early 50s) who were living in the capital cities of the four countries and who were mostly well educated. ${ }^{5}$ Eight of our interviewees were in same-sex living apart relationships, and 13 were in opposite sex ones. The duration of their relationships varied between a couple of months and 20 years.

The analysis involved a 'twin track' process, focusing first on each interviewee's 'lived life' (the biographical 'facts' recounted in the interview), second on their 'told story' of intimate life (the narrative), and then on the relationship between the two (Roseneil, 2012). Noting the diversity of cultural backgrounds, sexuality, life 'stage', relationship history, and length of living apart amongst the interviewees, we grouped our interviewees into five clusters on the basis of the main way in which each spoke about and understood their current living apart relationship: as (1) chosen; (2) temporary; (3) transitional; (4) undecided; and (5) unrecognisable. Each grouping represented different experiences of togetherness and apartness, but also reflected different journeys into living apart relationships, highlighting both the specificity of each individual's experience, and their socio-cultural and historic situatedness.

Previous research has used some of the distinctions that emerged from our analysis, but generally has less extensive typologies, and identifies less diversity than our research. For example, Roseneil (2006) distinguishes between 'undecidedly', 'regretfully', and 'gladly' apart couples, while Duncan and Phillips (2010) differentiate between 'dating' and 'partner' LATs. Levin (2004) also divides her sample into people who choose not to 
live together and those who cannot live together due to external constraints. Other studies classify non-cohabiting individuals on the basis of their relationship history, highlighting the importance of past intimate life events (Regnier-Loilier et al., 2009; Reimondos et al., 2011), which our study also demonstrated. However, we decided that relationship histories should be explored within the groupings based on subjective experiences of living apart, rather than the other way around.

When looking for explanations as to why individuals might cluster in particular groups, differences of class, education, age, gender, or sexuality do not seem to correlate in any clear way with our interviewees' subjective experiences of living apart. Ethnicity was in some cases connected to particular cultural norms about coupledom and hence linked to interviewees' experiences of living apart relationships as unrecognisable, as we discuss later. Relationship length seemed to be important only for the undecided group, which generally consisted of people in shorter relationships, of under 18 months, although it did not include all 'relationship novices'. Being married to, and having children with, the LAR partner ${ }^{6}$ was the most significant difference, as all interviewees in such circumstances (three cases) saw living apart as temporary. However, most of our sample was not married and had no children, with only two other people (in the transitional and the unrecognisable groups) having a child from a previous relationship.

Variations between countries are also difficult to extrapolate from such a small sample and with each cluster including representatives of most nationalities. Without any attempt to generalise from this, it is worth noting that, whilst the largest group, living apart as chosen consisted mainly of interviewees from Norway and the UK, the wealthier nations with stronger welfare states, with only one from Portugal and none from Bulgaria. In contrast, the unrecognisable LARs were Bulgarian and Portuguese, and although their small number (three cases) forecloses any meaningful discussion of cross-national differences, this might point to the existence of stronger traditional normativities around intimate life (see Roseneil et al., 2012). The suggested link between solo living and living apart relationships (Jamieson et al., 2009; Roseneil, 2006) was not observable in our sample: only three interviewees lived on their own (two in the UK and one in Bulgaria), 11 lived with family members (in three cases children only), and seven people shared housing with friends or housemates. The Bulgarian sample seemed to be more constrained and more often lived with relatives, whereas the UK LARs were independent from family, with our Portuguese and Norwegian interviewees more evenly divided between those who lived with relatives and those who did not. However, given our small sample, and the orientation of the biographical-narrative method 'to the exploration of life histories, lived situations and personal meanings' and its attention to 'the complexity and specificity of lived experience' (Roseneil, 2012: 130), we focus here on analysing subjective experiences of living apart, rather than on broader socio-economic and crossnational factors, which undoubtedly situate and mould the subjective experiences but are hard to extract in a meaningful way.

\section{Living Apart as Chosen}

The largest cluster of interviewees (seven of 21) was those whose narratives presented the living apart dimension of their relationship as chosen. Their stories resonate with 
research that sees living apart relationships as manifestations of the increasing possibility of diversity in ways of living intimate life (Levin, 2004; Roseneil, 2006). These were people who considered themselves to have chosen to live apart and were happy about being in such an arrangement for the long term. These interviewees shared a sense of their intimate arrangements being an alternative form of intimacy, yet their reasoning and subjective experiences of their relationships differed. There were people who celebrated their non-conventionality, others who found it quite comfortable, and yet others who had to undergo a long process of adjustment to what they regarded as a 'legitimate' form of intimacy.

This group consisted of three men and four women, aged between their early $30 \mathrm{~s}$ and their late 40s, from different ethnic backgrounds, who had been with their partners for between one and 10 years. They might all be described as being 'gladly apart' (Roseneil, 2006), but their individual routes to being in a living apart relationship had been quite different. There were people who had never been married or in a civil partnership and had never cohabited with a partner (Clara, Imran), and others who had previously cohabited with a partner on a long-term basis but had not been married (Vera, Lucy). ${ }^{7}$ There were people who were divorced (Jenny, Richard), as well as a majority Norwegian gay man, Paul, who was currently married and living with his partner but also had another open and long-term concurrent non-cohabiting relationship.

Concurrent relationships are usually excluded from studies of living apart relationships, in the attempt discussed above to focus on 'real' and 'steady' couples. For example, in their study on living apart, Haskey and Lewis (2006) did not ask married and cohabiting people if they were living apart from a partner, thus neglecting both the possibility of married couples living in separate households, and that both married and cohabiting couples might have concurrent relationships, even though they acknowledged that as many as 15 per cent of men and 9 per cent of women have such relationships. Paul's living apart relationship challenged normative notions of togetherness, and he explicitly took a political stand against the normalisation of same-sex relationships and the imposition of (hetero)normative, monogamous ideals of coupledom. Although he cherished his secure and long-established home-life with his husband, his living apart relationship with another man was also important to him. Whilst Paul was not against the idea of cohabitation per se, he could in some ways be grouped together with two other interviewees for whom living apart was a political statement (Liefbroer et al., 2012) about the importance of personal choice and of intimate relationships outside the conventional co-residential and sexually exclusive couple. Vera, a majority Portuguese heterosexual woman in her late 30s, positively embraced living apart as an intimate lifestyle. She had been living apart for several years and asserted that 'permanently sharing a space is not good for a relationship'. A previous relationship of eight years had been 'worn out' during its final two years when she and her partner lived together for the first time, which she saw as directly leading to the end of the relationship. She felt strongly that daily routines 'eroded' and 'exhausted' love relationships and was convinced that she would not change that viewpoint, even though she had experienced some pressure from partners who wanted to cohabit. At the time of the interview Vera was living with a gay male friend in a flat they co-owned, and she explained that she often referred to him, with a knowing irony, as 'my husband'. Their relationship was one of close friendship, 
sharing, and support and Vera was explicit that she preferred to live in this non-normative arrangement than with an intimate partner, an example of what Roseneil and Budgeon (2004) describe as a characteristically contemporary process of de-centring sexual relationships and prioritising friendship.

At the other end of the spectrum were Richard and Clara, who went through difficult processes of relationship negotiation and internal emotional struggle to reach the point where they now accepted living apart as a long-term arrangement. Tensions were visible in each of their narratives, which reflected at length on the pros and cons of living apart relationships. Richard, a British heterosexual divorced man in his late 40s, said that at the beginning both he and his divorced partner had wanted to 'take things quite slowly' and 'not put too many demands and pressure on each other', which their living apart arrangement allowed. Later on, however, he wanted to cohabit, but his partner had a strong preference to live apart. They had been together for about 10 years and Richard was certain that they would continue living like this in the future. In spite of some desire to cohabit, Richard felt that living apart allowed him 'a lot more freedom to be an individual' and that he was more protected from 'falling to pieces', should the relationship break down. Although he missed the intimate proximity of cohabitation, he found holidays difficult because he and his partner were 'in each other's pockets'. If not content, he seemed at least reconciled to living apart, and was able to reflect on both its negative and positive aspects.

Clara, a Norwegian majority heterosexual woman in her late 40s, explained that she initially thought that not cohabiting was a sign of a 'failed relationship' and that she had been preoccupied with the question 'why aren't we like other couples?'. Securing recognition of their coupledom from friends and family was also challenging, and Clara felt that she had 'worked on herself' a lot to reach a place where she felt confident in the legitimacy of their relationship and content with the closeness, care and excitement it offered. She currently appreciated how this arrangement allowed her to preserve the strong bonds she had with friends and family members and to maintain her care responsibilities for relatives.

However, most interviewees in this cluster did not seem to feel pressure to conform to normative forms of intimacy; on the contrary, they celebrated their non-conventionality. On the whole, this arrangement seemed to fit busy working lives and existing responsibilities, while allowing couples to have 'special time' when they met. The degree of choice and purposeful rebellion against norms varied between individuals and also over time. This occasionally included rather complex and contradictory negotiations of the meaning of such relationships and their social legitimacy. Yet this group can be seen as challenging some elements of conventional notions of intimacy in which coupledom is contiguous with (or moving towards) co-residence, sexual exclusivity, and life-long commitment. These interviewees might be seen as engaged in processes of queering personal relationships by de-centring conjugal relationships and sexual partnership and prioritising friendship (Roseneil and Budgeon, 2004).

\section{Living Apart as Temporary}

Four interviewees talked about living apart as a temporary feature of their relationship. In contrast to the first cluster, this second one includes people who were regretful about 
living apart from their partner. All spoke about being prevented from cohabiting by external factors, such as employment opportunities and immigration regulations. These interviewees were in relatively long-standing relationships of between three and 20 years, and all had cohabited with their partner in the past. They assumed that once circumstances allowed it, they would once more live together. Their ages ranged from early 30 s to early $50 \mathrm{~s}$, and their period of non-cohabitation from very recent to six years. Some had lived apart for long periods before this current separation and two of the interviewees (Zainab and Alika) had already made arrangements to start cohabiting again in the near future. For all interviewees in this group their current LAR was the most significant intimate relationship in their lives so far, and three of the four interviewees were married to their partner and had children together.

The extent to which couples are forced by circumstances to live separately, either temporarily or long term, is often discussed in the existing literature (Levin, 2004; Régnier-Loilier et al., 2009; Roseneil, 2006), with employment, education, care responsibilities, financial constraints, and national regulations regarding couple reunions amongst the factors mentioned most often. A recent study of living apart in the UK suggests that as many as 38 per cent of LAT interviewees gave some form of constraint as their main reason for living separately (Duncan et al., 2013). However, our analysis of narratives of temporarily living apart suggested that these interviewees' subjective experiences of living apart were more complex, involving both constraint and elements of choice, both past and present. For example, Zainab, who was a British Pakistani woman in her late 30s, had been married for 15 years but had been living apart from her husband for nearly half of that time, since she was deported from the USA for over-staying her visa (see Roseneil, 2013). Zainab struggled financially and practically after the deportation, having previously been highly dependent on her husband, but gradually built a life for herself and her children in London and started enjoying her new freedom. She decided not to go back to America a few years later when her husband's newly acquired US citizenship allowed her to rejoin him. Furthermore, she had mixed feelings about the fact that her husband was soon going to join her in the UK, and thought that they would have to re-negotiate how they would live together after her period of independence. Albay, who was a married Bulgarian man from an ethnic Turkish background in his early 50s, had also lived apart from his spouse for a long time - seven years. Living in a rented flat in Sofia, and geographically separated from his wife because they both wanted to keep their jobs, he was an example of the 'commuter couples' who have long been recognised by social researchers (Gerstel and Gross, 1984). Albay seemed reconciled to the situation and spoke about it in a rather matter-of-fact manner, focusing on the necessity to live apart 'in a country where there is never enough money'. He assumed that once his job allowed it, he would move back in with his family, but he was not clear when this might happen.

It seemed that where either the relationship or the living apart arrangement was relatively new to the interviewee, the constraint was felt more strongly and the separation was experienced as either posing a threat to the relationship or as difficult to accept. On the other hand, in cases when the couple had an established long-term relationship, or they had been living apart for longer, there was a stronger feeling that living separately did not threaten the relationship. 
Underneath the apparent coherence in the narratives of the interviewees who understood living apart as temporary and undesirable and who seemed to share a strong commitment to the existing relationship and expectation of future cohabitation, there was a range of subjective experiences and life journeys into living apart relationships. These interviews highlighted how feelings of belonging and attachment to the relationship were dynamic, changing across the interviewee's life, and over the course of the relationship, or the period of separation. They also suggested that the length of time people had lived apart and together influenced the extent to which they felt more or less secure when living apart, and that subjective happiness and satisfaction within the relationship itself influenced the extent to which individuals felt content with the non-cohabiting arrangement.

\section{Living Apart as Transitional}

The living apart as transitional group arguably represents the 'traditional' type of living apart relationship: a 'stepping stone' (Ermisch and Siedler, 2009; Haskey, 2005) towards more 'serious' and 'committed' long-term cohabiting relationships. Described by Duncan and Phillips (2010) as 'dating LATs', this cluster of interviewees saw their current living apart arrangement as temporary because there was an expectation and/or desire that they were on a trajectory towards a cohabiting relationship, which constituted 'proper' coupledom. This group consisted of three people who were in their early to late $30 \mathrm{~s}$, and had been with their partners for a period between five months and four years, and who expressed different degrees of certainty that cohabitation would come next. For example, Marianne, who was a majority Norwegian heterosexual woman in her late 30s, had been with her partner for the shortest time (five months), but already had strong expectations that their relationship would lead to long-term, stable cohabitation. In contrast to the tendency of some studies on living apart to assume that people in short-term relationships probably do not see themselves as a couple or are not seen as such by others and can, therefore, be excluded from samples, ${ }^{8}$ Marianne's narrative demonstrated that a relationship of relatively short duration can nonetheless be linked to strong feelings of togetherness and being in a couple, as well as to solid expectations of cohabitation. In this sense her account of her relationship was one of the most conventional of our "nonconventional' sample and also highlighted the problem with asserting a rather 'mechanical' notion of 'living apart togetherness' based on length of a relationship. Another interviewee, Bobby, who was a majority Bulgarian man in his 30s and had been with his partner for four years, expressed an equally strong expectation and desire to move in with his partner and spoke at length about their frustration that financial constraints were postponing their cohabitation.

On the other hand, Maggie, a majority Bulgarian lesbian in her early 30s who had been with her current partner for two years, offered a much more complex discussion of the positive and negative outcomes of possible cohabitation, which involved reflections on her own habits and preferences, as well as on socio-cultural expectations of 'appropriate' coupledom. Having often moved between cohabitation and living apart in the past, Maggie seemed to prefer to live together but could not do so, both because of the difficulty she experienced in openly showing her commitment to a person of the same sex, and due to financial 
constraints. Whilst being very unsure about when and how she and her partner might start living together, Maggie clearly saw cohabitation as a more desirable way of being together, one which would also represent a new stage in the relationship - a step towards 'creating a family', 'having tranquility in the relationship', and 'sharing everything'.

The interviewees in this cluster suggested that the relation between feelings of togetherness and the duration of the relationship was more complex than has tended to be assumed in existing studies of living apart relationships. Strong feelings of being together were present in the narratives of people who had been in a relationship for a fairly short period of time (Marianne), while feelings of being held apart (due to social norms or financial difficulties, for Maggie) were present in a much longer relationship. However, across quite different lengths of relationship, all three interviewees in this cluster shared the feeling that cohabitation was a marker of greater commitment and were hoping to live together in the future.

\section{Living Apart as Undecided}

Some ambivalence about the relationship, expressed as feelings of not being ready or it being too early in the relationship, is the single most common reason for living apart according to a recent UK survey (Duncan and Phillips, 2010: 118). The notion of 'undecidedly apart' (Roseneil, 2006) has been used to describe people who have not made an explicit decision about whether to cohabit or not, as their relationships 'were not constructed within a framework in which living together was something about which to decide' (2006: 8.15). According to Roseneil, 'undecidedness' was related either, in stable relationships, to not feeling the need to consider co-residence, or to feeling that the relationship was more contingent and less settled (2006: 8.15-16). Similarly, in our study, undecidedly living apart involved uncertainty about the future of the relationship, and some ambivalence about identifying as a couple at all.

This cluster comprised four women, from their early 30 s to their early 40 s, who had been in their non-cohabiting relationships for relatively short periods of between one month and about one and a half years. The unifying factor for this group was the feeling of uncertainty about the relationship, which also occupied a relatively small and insignificant part of the life stories offered in the interview. As people were not explicitly asked about living apart, this allowed them to decide when and in how much detail to speak about their current living apart relationship. For example, Pam, a British majority lesbian woman in her early 40s, who had been seeing her partner for just over two months, only mentioned this new 'relationship' towards the end of the interview; in the wider context of her life story, it was a minor feature. Two other interviewees felt uncertain whether to describe themselves as in a relationship. For example, Ashen, a Turkishborn woman in her late 30s living in the UK, felt that her 18-month relationship did not have the status of a 'proper' relationship. Despite this, she and her partner had an agreement that they would take care of each other if they did not find anybody else:

I am still with that person, but not to a 'relationship' extent. Ahm. Just some sort of agreement that if I don't find the partner that I want, and if he doesn't, then we will look after each other. 
Ashen had, then, a degree of commitment to her partner, who regularly visited her, and she often referred to his opinion during the interview, but she remained uncertain about the future of the relationship and seemed to be using it as a 'back-up' plan while looking for something else.

Rita, a majority Portuguese heterosexual woman in her late 30 s who had been with her partner for just under a year, expressed a different kind of ambivalence. Whilst she was quite emotionally invested in the relationship and wanted it to continue, her partner was very reticent about cohabiting. This seemed to create a lot of ambiguity for her because she believed co-residence to be necessary if she were to have children. She seemed unsure about the future of the relationship but hopeful about ending up with the 'right' partner: 'if this relationship is not the right one for me, I am still hopeful [that] I'll get myself a partner, even if it is when I'm an old lady, with my walking stick'. The idea of the 'right partner' was connected to expectations about having children and living together, even though Rita talked about enjoying certain aspects of living apart, such as 'being independent'.

So, accounts of 'undecidedly living apart' were sometimes related to being in a fairly recent relationship, in which the feeling of belonging to a couple was still being established (and whether this would in fact be the case was unclear) but where there was some sense of the on-goingness of the relationship. But Ashen and Rita, who had been with their partners for longer, shared doubts about whether this was the 'right' relationship for them, as it did not promise to provide what they sought. They saw this as related to the choice of partners, rather than the living arrangement or duration of the relationship. Hence, in some cases being undecidedly apart was about being in the 'early days' of the relationship (Pam, Hanna), whilst for others the relationship was more of a 'place-holder' until the 'real thing' happened (Ashen, Rita). Such emotional complexities about 'being together' tend to be concealed, we suggest, by the terminology of 'living apart together'.

\section{Living Apart Relationships as Unrecognisable}

An influential strand of sociological writing on the transformation of intimate life in recent years has emphasised the increasing possibility of choice in relation to sexual partnership, sexual behaviour, the timing and ordering of significant life events (such as cohabitation, marriage, and having children), and the organisation of living arrangements (Beck and Beck-Gernsheim, 1995; Giddens, 1992; Weeks et al., 2001). This understanding of personal relationships suggests that processes of individualisation and de-traditionalisation are productive of a greater cultural focus on the autonomy and authenticity of individuals, and argues that personal life is increasingly a matter of negotiation between individuals who are able to craft identities and relationships in new ways. Whilst our research on people living outside conventional couples and families offers considerable support for this, identifying the multifarious ways in which people are engaging in relational and personal experimentation, and showing how narratives of selfdetermination and autonomy were widespread amongst our interviewees, we also found that lived experiences of intimacy are still shaped in significant ways by powerful norms 
related to coupledom and procreation (see Roseneil et al., 2012). In respect of living apart relationships we found that in some socio-cultural contexts where cohabitation seemed impossible, living apart was determined by normative understandings of what constitutes acceptable intimacy and coupledom.

The interviewees whose accounts spoke about living apart from their partner in terms of the unrecognisability, and even 'impossibility', of their relationship were two Roma women in their early 30s - Raquel from Portugal and Toni from Bulgaria - and a majority Bulgarian gay man, Krasimir, who was also in his early 30 s. For various reasons, their relationships were positioned outside normative notions of acceptable coupledom, and lacked social recognition and visibility. On-going for between six months and 11 years, these relationships were experienced as 'impossible' forms of intimacy, even though all three interviewees spoke about their commitment to their partners.

Raquel spoke of having had several 'impossible loves' with men who were not Roma. She had wanted to marry some of them but duty to her parents had stopped her from doing this: 'in order to avoid heart-break for my parents, I've stopped myself. [...] If I had followed my own will, I would have married a non-Roma person a long time ago'. Krasimir had been in a same-sex non-residential relationship for five years, but his partner did not see himself as gay, and he felt that they had to keep their relationship secret. Krasimir explained that they often acted as friends rather then as partners when they were amongst others. Even though Krasimir identified as being in a living apart relationship, his told story revealed not only a complex knot of personal relations but also his own uncertainty about how he should describe this relationship. Issues related to Krasimir's expectation of sexual exclusivity, which was not fulfilled in this relationship, what he described as the inability of his partner to come out as gay and to have an open relationship, and the lack of social acceptance of same-sex intimacies, both in general and by his partner's family, were all intertwined in complicating the couple's relationship. Hence, the 'invisibility' offered by not living together was welcome to some extent, but Krasimir struggled to claim their coupledom because of its non-conventionality. $\mathrm{He}$ said that the relationship was 'very artificial', 'not real', and 'not true', while also describing it as 'the best thing' in his life and something he would not stop fighting for. Living apart seemed to function as a way of maintaining the secrecy, and hence the very possibility, of a same-sex relationship, in a cultural context where living openly in such a relationship seemed unimaginable. This was in direct contrast to the other Bulgarian interviewee in a same-sex relationship, Maggie, who saw living apart as limiting opportunities for intimacy, particularly physical intimacy, and who was hoping to cohabit in the future, as we discussed earlier.

Toni was also in a 'closeted' relationship, although an opposite-sex one. Her relationship was kept secret because her long-term partner was living with another woman with whom he had children. Toni's relationship had continued for 11 years, during which time she got pregnant and had a miscarriage. She clearly stated her preferences for a cohabiting relationship, for greater support from her partner, and her desire for them to have children together - her longing for 'a family'. Toni expressed her regret and dissatisfaction in very strong language, arguing that she had been 'used like a dog', and that her partner was 'a waste of time', and 'an obstacle' to getting the relationship she wanted. In 
spite of being regretful about living apart, Toni seemed entangled in this relationship and thought that it was too late in her life to pursue alternatives.

Each of these interviewees expressed on-going commitment, albeit rather tormented, to their unrecognised relationship, and perceived living apart as the only option that was available in the context of the absence, and seeming impossibility, of recognition from others of their coupledom. This 'impossibility' was strongly internalised and believed to be an external reality, a 'social fact' that could not be challenged. The unrecognised relationships described by our interviewees are not only unrecognised by their families, friends and communities; they also are missing from the existing research on living apart, which has, we suggest, focused too much on the identification of 'serious', and publicly recognised, and recognisable, relationships. However, we found that living apart can be a way to manage to pursue an intimate relationship that sits outside culturally dominant notions of acceptable coupledom and personal life.

\section{Conclusions}

To seeing living apart purely in terms of the diversification and opening up of choice that characterise contemporary intimate life (Levin and Trost, 1999) masks the complex ways in which 'togetherness' and 'apartness' feature simultaneously in non-cohabiting relationships. People in living apart relationships have varying experiences of receiving or being denied recognition and acceptance by others as belonging to a couple, and express differing degrees of desire for, and rebellion against, expectations that their relationship will 'progress' towards shared residence. In our study, experiences and meanings of 'togetherness' and 'apartness' varied across individual narratives of non-residential coupledom, as well as within individual interviewees' lives, with changing degrees of choice and constraint marking the attempts of individuals and couples to negotiate being together in the context of other factors, such as established personal routines, desire for independence, financial constraints, and existing commitments to paid work, care, friends, and families.

The largest group of interviewees in our sample, whose accounts suggested that they were living apart by choice, preferred, and sometimes celebrated, living apart as an alternative form of intimacy. For them, living apart was a state of being together in a committed and long-term way, whilst also being apart in a meaningful and welcome manner. Others who described their living apart as temporary or transitional seemed to prioritise shared residence as an intimate arrangement and were separated by external factors but still valued some aspects of 'apartness', such as greater independence and ability to follow work commitments. For those who were undecided about their living apart relationship, being apart from their partner allowed space for the relationship to unfold, or for other relationships to develop. Finally, living apart in a relationship that was unrecognised by others allowed some couples to be together in contexts where alternative arrangements seemed impossible, so that formal residential apartness allowed 'under the radar' togetherness.

Whilst this clustering of our interviewees' predominant narratives of their living apart relationships was quite distinct, and we were able, relatively easily, to locate each interviewee alongside others with similar narratives, their narratives were also cross-cut 
by common feelings of emotional attachment to their LAR partner, stories of giving and receiving care and support, and descriptions, to a greater or lesser extent, of both the benefits and constraints of the arrangement. Living apart from a partner seemed to enable a significant degree of flexibility and fluidity within the relationship, by allowing the combination of intimacy within coupledom and life 'outside' the relationship. Moreover, discussions of 'togetherness' in the interviews were far from exclusively about intimate sexual relationships. Across the clusters that we have identified, our interviewees variously expressed strong feelings of attachment to family members and friends, of belonging to networks and communities of identity and interest, and sometimes talked about 'being together' with concurrent intimate partners. There was also a strong sense, for many interviewees, of the importance of staying true to themselves and their own needs, and a desire to preserve and protect their existing way of life, with its routines and security. Hence, we argue for the importance of attending to the many ways in which 'togetherness' and 'apartness' are complex experiences in living apart relationships. We point too to the need for sociologists to cast our gaze beyond a focus just on the more readily intelligible couple relationships, and to admit into sociological research on intimate life those that are more unusual or counternormative, and that are sometimes hidden and culturally unrecognisable.

\section{Funding}

EU Framework 6 Integrated Project (grant number 028746), directed by Beatrice Halsaa, Sasha Roseneil, Solveig Bergman and Sevil Sümer.

\section{Notes}

1. Perhaps including 'together' alongside 'apart' in coining the term 'living apart together' serves as a rhetorical move, but we prefer a more simply descriptive term that leaves the 'togetherness' of the 'living apart' relationship open to investigation.

2. FEMCIT - Gendered Citizenship in Multicultural Europe: the impact of contemporary women's movements - was an EU Framework 6 Integrated Project (grant number 028746), directed by Beatrice Halsaa, Sasha Roseneil, Solveig Bergman and Sevil Sümer (see Halsaa et al., 2012). The Intimate Citizenship Work Package, on which this article is based, was directed by Sasha Roseneil. See http://www.femcit.org

3. We interviewed 67 people ( 41 women; $25 \mathrm{men}$ ), from their late $20 \mathrm{~s}$ to early $50 \mathrm{~s}$, who were one or more of the following: living apart; unpartnered; lesbian/gay/in a same-sex relationship; sharing housing.

4. Other sources give lower proportion of LATs in Norway - 10\% in Levin (2004).

5. Fifteen people had an undergraduate or higher degree; three people had finished secondary school and three had studied until 16 years or less. Our sample is skewed towards an older age group than that identified as the most common age to be in a living apart relationship (mid to late 20s) in the UK (Duncan and Phillips, 2010).

6. We use the term 'partner' without suggesting that this was the interviewees' own terminology. In Norway there is a well-established word for a living apart partner ('særbo'); in the UK the term 'LAT' is gaining some recognition through media discussions, often stimulated by academic research, but in Bulgaria and Portugal there is no corresponding terminology.

7. All names are pseudonyms.

8. For example, Ermisch (2000) excluded people in relationship for less than six months and Haskey and Lewis (2006) did not include any people who had been with their partner for less than a year. 


\section{References}

Allan G, Hawker S and Crow G (2001) Family diversity and change in Britain and Western Europe. Journal of Family Issues 22(7): 819-33.

Beck U and Beck-Gernsheim E (1995) The Normal Chaos of Love. Oxford: Polity Press.

Beck-Gernsheim E (2007) Transnational lives, transnational marriages: A review of the evidence from migrant communities in Europe. Global Networks 7(3): 271-88.

Duncan S and Phillips M (2010) People who live apart together (LATs) - how different are they? Sociological Review 58(1): 112-34.

Duncan S, Carter J, Phillips M, Roseneil S and Stoilova M (2013) Why do people live apart together? Families, Relationships and Societies 2(3): 323-38.

Ermisch J (2000) Personal Relationships and Marriage Expectations: Evidence from the 1998 British Household Panel Study. ISER Research Working Paper. Colchester: University of Essex.

Ermisch J and Siedler T (2009) Living apart together. In: Brynin M and Ermisch J (eds) Changing Relationships. New York: Routledge, 29-43.

Gerstel N and Gross H (1984) Commuter Marriage: A Study of Work and Family. London: Guilford Press.

Giddens A (1992) The Transformation of Intimacy. Cambridge: Polity Press.

Halsaa B, Roseneil S and Sümer S (eds) (2012) Remaking Citizenship in Multicultural Europe: Women's Movements, Gender and Diversity. London: Palgrave Macmillan.

Haskey J (2005) Living arrangements in contemporary Britain: Having a partner who usually lives elsewhere and living apart together (LAT). Population Trends 122(winter): 35-45.

Haskey J and Lewis J (2006) Living-apart-together in Britain: Context and meaning. International Journal of Law in Context 2(1): 37-48.

Holmes M (2004) An equal distance? Individualisation, gender and intimacy in distance relationships. Sociological Review 52(2): 180-200.

Jamieson L, Wasoff F and Simpson R (2009) Solo-living, demographic and family change: The need to know more about men. Sociological Research Online 14(2/3).

Liefbroer A, Seltzer J and Poortman AR (2012) Why do intimate partners not live together? Understanding diversity in LAT relationships across Europe. Extended abstract European Population Conference, 13-16 June, Stockholm, Sweden.

Levin I (2004) Living apart together: A new family form. Current Sociology 52(2): 223-40.

Levin I and Trost J (1999) Living apart together. Community, Work and Family 2(3): 279-94.

Régnier-Loilier A, Beaujouan É and Villeneuve-Gokalp C (2009) Neither single, nor in a couple. Demographic Research 21(4): 75-108.

Reimondos A, Evans E and Gray E (2011) Living apart together (LAT) relationships in Australia. Family Matters 87(1): 43-55.

Roseneil S (2006) On not living with a partner: Unpicking coupledom and cohabitation. Sociological Research Online 11(3).

Roseneil S (2012) Using biographical narrative and life story methods to research women's movements: FEMCIT. Women's Studies International Forum 35(3): 129-31.

Roseneil S (2013) The vicissitudes of post-colonial citizenship and belonging in late liberalism. In: Roseneil S (ed.) Beyond Citizenship? Feminism and the Transformation of Belonging. London: Palgrave, 231-65.

Roseneil S and Budgeon S (2004) Cultures of intimacy and care beyond 'the family': Personal life and social change in the early 21 st century. Current Sociology 52(2): 135-59.

Roseneil S, Crowhurst I, Hellesund T, Santos AC and Stoilova M (2012) Remaking intimate citizenship in multicultural Europe. In: Halsaa B, Roseneil S and Sumer S (eds) Remaking Citizenship in Multicultural Europe: Women's Movements, Gender and Diversity. London: Palgrave Macmillan, 41-69. 
Sobotka T and Testa RM (2008) Attitudes and intentions towards childlessness in Europe. In: Höhn C, Avramov D and Kotowska I (eds) People, Population Change and Policies. Berlin: Springer, 177-211.

Strohm C, Selzer JA, Cochran SD and Mays V (2009) 'Living apart together' relationships in the United States. Demographic Research 21(7): 177-214.

UN (2012) Generations and Gender Programme: Survey Instruments. New York: United Nations. UNECE (2010) Statistical Database: Private Households by Household Type. Available at: http:// w3.unece.org/pxweb/

Weeks J, Heaphy B and Donovan C (2001) Same Sex Intimacies: Families of Choice and other Life Experiments. London: Routledge.

Wengraf T (2001) Qualitative Research Interviewing. London: Sage.

Mariya Stoilova is a researcher at OnePlusOne and an Honorary Research Fellow at the Birkbeck Institute for Social Research at Birkbeck, University of London, UK. Her research on intimacy, family transformations, and gendered citizenship focuses on UK and Eastern European dynamics, policy implications, and practice development. Her recent publications include 'Mind the gap: The changing face of gender (in)equality in Bulgaria after 1989' (in Ramen and Hassenstab, eds, Palgrave, forthcoming), 'Why do people live apart together?' (Families, Relationships and Societies 2(3): 323-38, with Duncan et al., 2013), Citizenship and Reproduction/Reproducing Citizens (special issue of Citizenship Studies, ed. with Roseneil et al., 2013) and the co-authored book The Tenacity of the Couple Norm (Palgrave, forthcoming).

Sasha Roseneil is Professor of Sociology and Social Theory, and Director of the Birkbeck Institute for Social Research at Birkbeck, University of London, UK. She is also Professor II in Sociology in the Centre for Gender Research, University of Oslo, Norway. She was Deputy Director of the EU Framework 6 Project, FEMCIT, and lead the FEMCIT research on intimate citizenship on which this paper is based. Her recent publications include Social Research after the Cultural Turn (Palgrave, 2010, ed. with Stephen Frosh), Remaking Citizenship in Multicultural Europe: Women's Movements, Gender and Diversity (Palgrave, 2012, ed. with Beatrice Halsaa and Sevil Sümer), Beyond Citizenship: Feminism and the Transformation of Belonging (Palgrave, 2013) and Citizenship and Reproduction/Reproducing Citizens (special issue of Citizenship Studies, ed. with Crowhurst et al., 2013). The co-authored book The Tenacity of the Couple Norm is forthcoming (Palgrave).

Isabel Crowhurst is Lecturer in Sociology and Criminology at Kingston University, London, UK. Her research on gender, sexuality and migration focuses on the regulation and practices of intimacy and commercial sex. She is chair of COST Action IS1209 'Comparing European Prostitution Policies: Understanding Scales and Cultures of Governance' (ProsPol), and is currently completing a monograph entitled Regulating Migrant Prostitution.

Tone Hellesund is an ethnologist, university librarian and former senior researcher at the Stein Rokkan Centre for Social Studies, University of Bergen, Norway. She has worked on historical and contemporary transformations of intimacies and sexualities. She is the author of Kapitler fra singellivets historie [Chapters from the History of Single Life] (Universitetsforlaget, 2003) and Identitet på liv og død. Marginalitet, homoseksualitet og selvmord [Identities for Life and Death: Marginality, Homosexuality and Suicide] (Spartacus, 2008).

Ana Cristina Santos is a senior researcher at the Centre for Social Studies, University of Coimbra, and Honorary Research Fellow at the Birkbeck Institute for Social Research, University of London. She has been involved in a number of research projects exploring issues of gender, sexual and 
reproductive rights, citizenship, and human rights. Since 2012, she has been the Principal Investigator of a research project on disabled women and intimate citizenship funded by the Portuguese Foundation for Science and Technology. In 2013 she was awarded a 5-year research grant by the European Research Council to lead a study on Citizenship, Care and Choice: The Micropolitics of Intimacy in Southern Europe. Her most recent book is Social Movements and Sexual Citizenship in Southern Europe (Palgrave Macmillan, 2013). Vice-chair of the Sexuality Research Network of the European Sociological Association, Cristina is also an activist in the LGBT/queer and feminist movements in Portugal.

Date submitted March 2013

Date accepted November 2013 